\title{
THERMAL STABILITY OF FIELD- AND STRESS-INDUCED ANISOTROPY IN NANOCRYSTALLINE Fe-BASED AND AMORPHOUS Co-BASED ALLOYS
}

\author{
N.V. DMITRIEVA*, V.A. LUKSHINA, \\ G.V. KURLYANDSKAYA and A.P. POTAPOV \\ Institute of Metal Physics UD RAS, Kovalevskaya St. 18, \\ Ekaterinburg 620219, Russia
}

(Received in final form 28 September 1997)

\begin{abstract}
Thermal stability of induced magnetic anisotropy (IMA) was studied in a course of subsequent annealings without any external effects for already field- or stress-annealed specimens of the nanocrystalline $\mathrm{Fe}_{73.5} \mathrm{Cu}_{1} \mathrm{Nb}_{3} \mathrm{Si}_{13.5} \mathrm{~B}_{9}$ and amorphous $\mathrm{Fe}_{3} \mathrm{Co}_{67} \mathrm{Cr}_{3} \mathrm{Si}_{15} \mathrm{~B}_{12}$ alloys. For these alloys the dependence of IMA thermal stability on the magnitude of the IMA constant $\left(K_{\mathrm{u}}\right)$ and temperature of stress-annealing was investigated. For the nanocrystalline alloy thermal stability of field- and stress-induced anisotropy with identical $K_{\mathrm{u}}$ was compared. It was shown that nanocrystalline specimens with identical $K_{\mathfrak{u}}$ values after field- or stress-annealing have identical thermal stability of IMA. This can point to a similarity of the mechanisms of IMA formation after field- or stress-annealings. Thermal stability of stress-induced anisotropy in the nanocrystalline alloy with $K_{\mathrm{u}}$ value less than $1000 \mathrm{~J} / \mathrm{m}^{3}$ and the amorphous alloy with $K_{\mathrm{u}}$ less than $100 \mathrm{~J} / \mathrm{m}^{3}$ depends on the value of $K_{\mathrm{u}}$. For both stress-annealed nanocrystalline and amorphous alloys magnetic anisotropy induced at higher temperatures is more stable because more long-range and energy-taking processes take place at these temperatures.
\end{abstract}

Keywords: Induced magnetic anisotropy; Thermal stability; Thermomagnetic and thermomechanical treatments; Nanocrystalline and amorphous alloys

\section{INTRODUCTION}

It is known that amorphous and nanocrystalline materials show the highest soft magnetic properties. The required level of soft magnetic

* Corresponding author. 
properties is reached by different kinds of anisotropies induced in these materials by various treatments. These are thermomagnetic treatments in d.c., a.c. and high frequency magnetic fields, quenching from the Curie temperature into water (Glazer et al., 1992; 1994), thermomechanical treatment which is the only effective one in ferromagnetics with low Curie temperature (Kurlyandskaya et al., 1996). The practical use of soft magnetic materials with induced magnetic anisotropy is determined by their thermal stability. In present work the thermal stability of fieldand stress-induced anisotropy in the amorphous $\mathrm{Fe}_{3} \mathrm{Co}_{67} \mathrm{Cr}_{3} \mathrm{Si}_{15} \mathrm{~B}_{12}$ and the nanocrystalline $\mathrm{Fe}_{73.5} \mathrm{Cu}_{1} \mathrm{Nb}_{3} \mathrm{Si}_{13.5} \mathrm{~B}_{9}$ alloys is studied, the thermal stability of these anisotropies is compared. This is important both for the estimation of the thermal stability of the magnetic properties and for understanding of the nature of the induced magnetic anisotropy (IMA).

\section{EXPERIMENTAL}

The alloy ribbons were produced by melt quenching on rotational disc in air. In order to achieve soft magnetic properties Fe-based amorphous ribbons were to be nanocrystallized by annealing at $530^{\circ} \mathrm{C}$ for $1 \mathrm{~h}$ (NCA). Thermomagnetic treatment (TMT) in transverse d.c. magnetic field $H=2.5 \cdot 10^{5} \mathrm{~A} / \mathrm{m}$ always was carried out during NCA. Thermomechanical treatment (TMechT) was carried out either simultaneously with NCA (regime 1) or after NCA (regime 2) at different temperatures: $300^{\circ} \mathrm{C}, 400^{\circ} \mathrm{C}$ and $530^{\circ} \mathrm{C}$ for 4,2 and $2 \mathrm{~h}$, respectively (Lukshina et al., 1996). For all Co-based amorphous specimens preliminary $1 \mathrm{~h}$ annealing at $350^{\circ} \mathrm{C}$ for stress releasing was performed. Field-annealing for this material is not effective because the Curie temperature is too low $\left(160^{\circ} \mathrm{C}\right)$ (Kurlyandskaya et al., 1996). Stress-annealing was carried out at $250^{\circ} \mathrm{C}$ and $350^{\circ} \mathrm{C}$ for 4 and $1 \mathrm{~h}$, respectively. These exposures were necessary for obtaining ultimate magnitudes of IMA constants. The magnitudes of IMA constants were determined from the hysteresis loops according to the formula $K_{\mathrm{u}}=-\frac{1}{2}\left(M_{\mathrm{s}} H_{\mathrm{s}}\right)$, where $M_{\mathrm{s}}$ is the saturation magnetization, $H_{\mathrm{s}}$ is the magnetic field in which saturation magnetization is achieved.

Thermal stability of induced magnetic anisotropy was studied in a course of subsequent annealings without any external effects for already field- or stress-annealed specimens of the alloys mentioned above. 


\section{RESULTS AND DISCUSSION}

For the nanocrystalline alloy thermal stability of the magnetic anisotropy was studied using the samples after TMT with $K_{\mathrm{u}}=100$ and $350 \mathrm{~J} / \mathrm{m}^{3}$ and after TMechT (regime 1) with $K_{\mathrm{u}}$ from 400 to $4000 \mathrm{~J} / \mathrm{m}^{3}$. The specimens with different $K_{\mathrm{u}}$ were annealed without any external effects for $1 \mathrm{~h}$ at progressively increasing temperatures in steps of $50 \mathrm{~K}$, starting from $200^{\circ} \mathrm{C}, K_{\mathrm{u}}$ was measured at room temperature after each annealing.

It was found that the specimens with $K_{\mathrm{u}}$ about $1000 \mathrm{~J} / \mathrm{m}^{3}$ and more had the most thermally stable magnetic anisotropy. It was stable during $1 \mathrm{~h}$ annealing at $450^{\circ} \mathrm{C}$. For $K_{\mathrm{u}}$ less than $1000 \mathrm{~J} / \mathrm{m}^{3}$ the thermal stability depends on the magnitude of $K_{\mathrm{u}}$; the less the magnitude, the less the temperature up to which $K_{\mathrm{u}}$ was stable. Maximal $K_{\mathrm{u}}$ magnitudes obtained after TMT usually were equal to $100-150 \mathrm{~J} / \mathrm{m}^{3}$. These values were essentially less than the ones after TMechT. So, thermal stability of $K_{\mathrm{u}}$ which we can obtain after TMT is less than that after TMechT (see Fig. 1).

For some specimens Fig. 1 displays the relative variation of the constant of IMA, $K_{\mathrm{u}}(t) / K_{\mathrm{u}}$ depending on the $(1 \mathrm{~h})$ annealing temperature; $K_{\mathrm{u}}$ is the magnitude of the anisotropy constant immediately after TMT or TMechT and $K(t)$ is the magnitude after annealing without any external effects following TMT or TMechT. It can be seen from Fig. 1 that the less

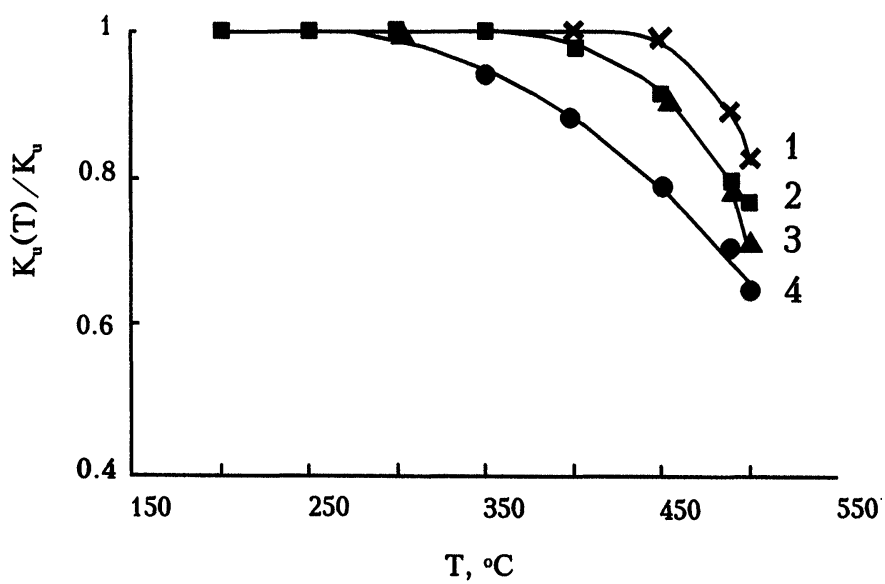

FIGURE 1 Relative $K_{\mathrm{u}}$ variation after stress and magnetic field-free annealing for $1 \mathrm{~h}$ at different temperatures for the nanocrystalline alloy. Curves 1 and 2: for $K_{\mathrm{u}}$ obtained after TMechT and equal to 4000 and $400 \mathrm{~J} / \mathrm{m}^{3}$, respectively; curves 3 and 4 : for $K_{\mathrm{u}}$ obtained after TMT and equal to 350 and $100 \mathrm{~J} / \mathrm{m}^{3}$, respectively. 
the magnitude of $K_{\mathrm{u}}$ the less the $1 \mathrm{~h}$ annealing temperature up to which $K_{\mathrm{u}}$ does not yet decrease (compare curves 1,2,3 and 4). It should be noticed that if the magnitudes of $K_{\mathrm{u}}$ obtained after TMT and TMechT are close to each other their thermal stabilities are equal, as well (compare curves 2 and 3). It can point to a similarity of mechanisms of magnetic anisotropy induced after TMT and TMechT, as well.

Analogous investigations of the thermal stability of IMA for Co-based amorphous alloy show that magnetic anisotropy induced by TMechT is stable after $1 \mathrm{~h}$ annealing without any stress at $240^{\circ} \mathrm{C}$ for specimens with $K_{\mathrm{u}}$ values being equal or more than $100 \mathrm{~J} / \mathrm{m}^{3}$. For this amorphous alloy we considered the dependence of thermal stability on the magnitudes of $K_{\mathrm{u}}$ obtained after stress-annealing. The samples with $K_{\mathrm{u}}$ from 25 to $500 \mathrm{~J} / \mathrm{m}^{3}$ were prepared by TMechT at $350^{\circ} \mathrm{C}$ for $1 \mathrm{~h}$ with $\sigma$ from 80 to $1400 \mathrm{MPa}$, respectively. Figure 2 shows the change of $K_{\mathrm{u}}$ against annealing time at $260^{\circ} \mathrm{C}$ without any load. It is seen that specimens with $K_{\mathfrak{u}}$ from 500 (curve 1) to $100 \mathrm{~J} / \mathrm{m}^{3}$ (curve 2) have the same thermal stability; the experimental points are situated on the same curve. The specimen with $K_{\mathrm{u}}=25 \mathrm{~J} / \mathrm{m}^{3}$ has less thermal stability; the respective curve 3 runs below curve 1 . Thermal stability of stress-induced anisotropy in amorphous alloys with $K_{\mathrm{u}}$ values less than $100 \mathrm{~J} / \mathrm{m}^{3}$ depends on the $K_{\mathrm{u}}$ value: the less $K_{\mathrm{u}}$, the less the thermal stability.

For the above-mentioned alloys the influence of TMechT temperature on the thermal stability of IMA was investigated. For the

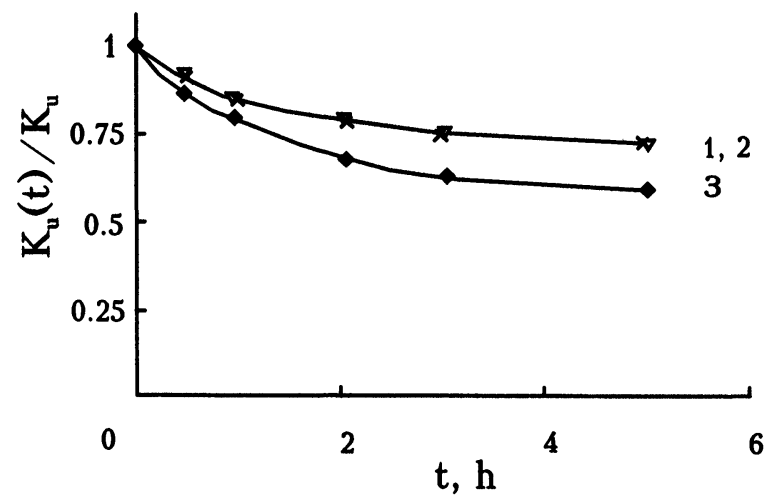

FIGURE 2 The relative change of IMA constant against the annealing time at $260^{\circ} \mathrm{C}$ without any load for the amorphous alloy. Starting $K_{\mathrm{u}}\left(\right.$ in $\left.\mathrm{J} / \mathrm{m}^{3}\right)=500$ (curve 1 ), 100 (curve 2), 25 (curve 3) induced by TMechT with various $\sigma$ at $350^{\circ} \mathrm{C}$ for $1 \mathrm{~h}$. 
nanocrystalline alloy after TMechT by regime 2 , we took three samples with the same $K_{\mathrm{u}}\left(=150 \mathrm{~J} / \mathrm{m}^{3}\right)$ obtained at different temperatures of TMech $\left(530^{\circ} \mathrm{C}, 400^{\circ} \mathrm{C}\right.$ and $\left.300^{\circ} \mathrm{C}\right)$ and different loads $(25,160$ and $320 \mathrm{MPa}$, respectively). The samples were treated by TMechT at $530^{\circ} \mathrm{C}$, $400^{\circ} \mathrm{C}$ and $300^{\circ} \mathrm{C}$ for 2,2 and $4 \mathrm{~h}$, respectively. These exposures were necessary for obtaining ultimate magnitudes of IMA constants. For the Co-based amorphous alloy two samples were prepared with the same $K_{\mathrm{u}}$ values, which were equal to $200 \mathrm{~J} / \mathrm{m}^{3}$, induced at various temperatures of TMechT: $350^{\circ} \mathrm{C}(1 \mathrm{~h}, \sigma=500 \mathrm{MPa})$ and $250^{\circ} \mathrm{C}(4 \mathrm{~h}, \sigma=1500 \mathrm{MPa})$.

These samples were annealed without any load: at $260^{\circ} \mathrm{C}$ for Co-based amorphous alloy and at $300^{\circ} \mathrm{C}$ for the nanocrystalline alloy. In certain intervals of time, the samples were cooled to room temperature, and the magnetic anisotropy constant, $K_{\mathrm{u}}(t)$, was measured. Figures 3 and 4 show the relative changes of the IMA constant, $K_{\mathrm{u}}(t) / K_{\mathrm{u}}$, against the annealing time $\left(K_{\mathfrak{u}}\right.$ is the IMA constant value immediately after TMechT). $K_{\mathrm{u}}(t) / K_{\mathrm{u}}=1$ for $t=0$, which conforms to a state immediately after TMechT.

Figures 3 and 4 show that the IMA constant induced at higher TMechT temperature decreases slowly with the exposure time. The $K_{\mathrm{u}}$ of the nanocrystalline alloy sample that was subjected to TMechT at $530^{\circ} \mathrm{C}$ remains virtually unchanged after $4-5 \mathrm{~h}$ annealing at $300^{\circ} \mathrm{C}$

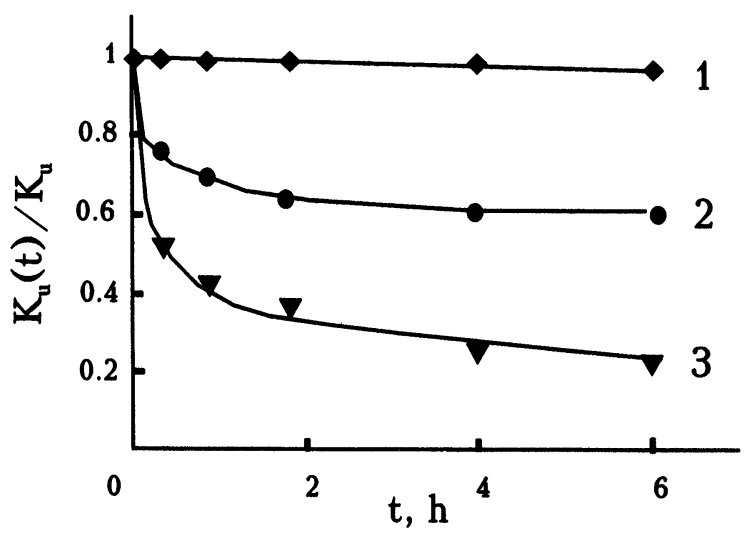

FIGURE 3 Variation of $K_{\mathrm{u}}$ depending on the stress-free annealing time at $300^{\circ} \mathrm{C}$ for the samples of the nanocrystalline alloy treated by regime 2 under the following conditions: NCA at $530^{\circ} \mathrm{C}$ for $1 \mathrm{~h}+\mathrm{TMT}$ at (1) $530^{\circ} \mathrm{C}$ for $2 \mathrm{~h}$ and $\sigma=25 \mathrm{MPa}$; (2) $400^{\circ} \mathrm{C}$ for $2 \mathrm{~h}$ and $\sigma=160 \mathrm{MPa}$; and $(3) 300^{\circ} \mathrm{C}$ for $4 \mathrm{~h}$ and $\sigma=320 \mathrm{MPa}$. (After all these TMechTs the magnitude of $K_{\mathrm{u}}$ was the same, equal to $150 \mathrm{~J} / \mathrm{m}^{3}$.) 


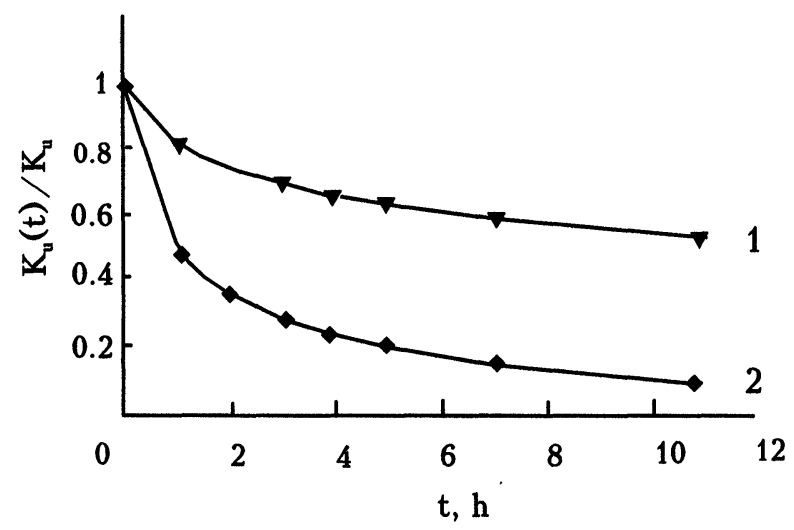

FIGURE 4 The relative change of starting $K_{\mathrm{u}}=200 \mathrm{~J} / \mathrm{m}^{3}$ induced by TMechT at $350^{\circ} \mathrm{C}$ with $\sigma=500 \mathrm{MPa}$ for $1 \mathrm{~h}$ (curve 1) and at $250^{\circ} \mathrm{C}$ with $\sigma=1500 \mathrm{MPa}$ for $4 \mathrm{~h}$ (curve 2) following annealing at $260^{\circ} \mathrm{C}$ without any load for the amorphous alloy.

(curve 1, Fig. 3); after the TMechT at $400^{\circ} \mathrm{C} K_{\mathrm{u}}$ decreases by $40 \%$ (curve 2, Fig. 3); and annealing at $300^{\circ} \mathrm{C}$ without load after TMech T at $300^{\circ} \mathrm{C}$ decreases $K_{\mathrm{u}}$ by $75 \%$ (curve 3, Fig. 3). For the Co-based amorphous alloy after $10 \mathrm{~h}$ of annealing without any load, $K_{\mathrm{u}}$ decreases by $50 \%$ if a sample was stress-annealed at $350^{\circ} \mathrm{C}$ and by $90 \%$ if the sample was stressannealed at $250^{\circ} \mathrm{C}$ (Fig. 4). The higher thermal stability of IMA induced by $\mathrm{TMechT}$ at $350^{\circ} \mathrm{C}$ for Co-based amorphous alloy and at $530^{\circ} \mathrm{C}$ for the nanocrystalline alloy shows that an increase of the TMechT temperature not only accelerates the diffusion processes but gives rise to more longrange and energy-taking processes, as well. Indeed for Co-based amorphous alloys the activation energies, estimated for a change of $50 \%$ of $K_{\mathrm{u}}$ from the kinetic curves of the IMA relaxation, have the following values: $2.2 \mathrm{eV}$ for IMA induced at $350^{\circ} \mathrm{C}$ and $1.9 \mathrm{eV}$ for IMA induced at $250^{\circ} \mathrm{C}$.

\section{CONCLUSIONS}

From the above the following conclusions can be made:

1. The induced magnetic anisotropy (IMA) is stable after $1 \mathrm{~h}$ annealing at: (a) $450^{\circ} \mathrm{C}$ for the nanocrystalline alloy after TMechT by regime 1 with $K_{\mathrm{u}}$ value being equal to or more than $1000 \mathrm{~J} / \mathrm{m}^{3}$; (b) $300^{\circ} \mathrm{C}$ for the nanocrystalline alloy after TMT with $K_{\mathrm{u}}$ value about $100 \mathrm{~J} / \mathrm{m}^{3}$; 
(c) $240^{\circ} \mathrm{C}$ for amorphous alloy with $K_{\mathrm{u}}$ value being equal to or more than $100 \mathrm{~J} / \mathrm{m}^{3}$.

2. Thermal stability of stress-induced anisotropy in the nanocrystalline alloy with $K_{\mathrm{u}}$ value less than $1000 \mathrm{~J} / \mathrm{m}^{3}$ and in the amorphous alloy with $K_{\mathrm{u}}$ value less than $100 \mathrm{~J} / \mathrm{m}^{3}$ depends on the value of $K_{\mathrm{u}}$ : the less $K_{\mathrm{u}}$, the less the thermal stability.

3. It is shown that for both stress-annealed nanocrystalline by regime 2 and amorphous alloys magnetic anisotropy induced at higher temperatures is more stable because more long-range and energy-taking processes take place at higher temperature of TMechT.

4. Identical thermal stability for nanocrystalline specimens with identical $K_{\mathrm{u}}$ values after TMT and TMechT points to a similar nature of field- and stress-induced anisotropy.

\section{Acknowledgements}

This work was supported by the Russian Fund for Basic Research, pr. No. 96-02-16000.

\section{References}

Glazer, A.A., Shulika, V.V. and Potapov, A.P. (1992). Domain structure destabilization of amorphous alloy by thermomagnetic treatment in high frequency field. Docladi Academii Nauk (Russian), 324(6), 1191-1193.

Glazer, A.A., Shulika, V.V. and Potapov, A.P. (1994). Effect of induced magnetic anisotropy upon static and dynamic magnetic properties of amorphous soft magnetic alloys with different magnetostriction. The Physics of Metals and Metallography, 78(4), 383-387.

Kurlyandskaya, G.V., Dmitrieva, N.V., Zayarnaya, T.Ye., Lukshina, V.A. and Potapov, A.P. (1996). The thermomechanical treatment of an amorphous Co-based alloy with a low Curie temperature. Journal of Magnetism and Magnetic Materials, 160, 307-308.

Lukshina, V.A., Dmitrieva, N.V. and Potapov, A.P. (1996). Thermomechanical treatment of nanocrystalline $\mathrm{FeCuNbSiB}$ alloy: induced magnetic anisotropy and its thermal stability. The Physics of Metals and Metallography, 82(4), 376-378. 